\title{
Estágio Atual do Conhecimento sobre Fitólitos no Brasil
}

\author{
Current Knowledge about Phytoliths in Brazil
}

\author{
Leandro Domingos Luz ${ }^{1,2}$,Elaine Cristina Zavadovski Kalinovski², Mauro Parolin ${ }^{3}$ Edvard Elias de Souza Filho ${ }^{4}$ \\ 1 Laboratório de Estudos Paleoambientais da Fecilcam. Universidade Estadual do Paraná,Campo Mourão, Paraná, Brasil. leandroluz07@gmail.com \\ 2 Programa de Pós-graduação em Geografia. Universidade Estadual de Maringá, Maringá, Paraná Brasil \\ 3 Laboratório de Estudos Paleoambientais da Fecilcam. Universidade Estadual do Paraná,Campo Mourão, Paraná, Brasil. \\ 4 Universidade Estadual de Maringá, Maringá, Paraná Brasil.
}

\section{Manuscrito:}

Recebido: 2/8/2013

Corrigido: 29/8/2014

Aceito: 9/9/2014

Citation: Luz L.D., Kalinovski E.C.Z., Parolin M., Souza Fo E.E.de. 2015. Estágio Atual do Conhecimento sobre Fitólitos no Brasil. Terræ Didatica, 11(1):52-64. < http://www. ige.unicamp.br/terraedidatica/>.

Keywords: Phytoliths, Modern plants, Paleoenvironmental reconstruction.

\begin{abstract}
The authors present the results of an analytical study of research on phytoliths, micrometric bodies of biogenic opal precipitated in plant tissues, produced in Brazil up to June 2013. Research on phytoliths are recent in Brazil and has grown up considerably in recent years. Thus, this paper aims to provide future researchers with an introduction the current status of research on this topic. As the research methodology the site "Periódicos CAPES" to access articles in journals as well as information about theses and monographs from national and international researchers. Simple abstracts published in events were not part of the survey. The results indicated that research on application (proxy data) has been more numerous (63.5\%) than that relating to identification of phytoliths in modern plants (36.5\%), highlighting the urgency of research for this purpose. Although phytoliths are widely used in archaeological studies in Brazil, just two articles have been published. Finally, we presented a spatialization of the results, which demonstrated the wide disparity in scientific production, concentrated mostly in the center south region of Brazil, more precisely in the states of Rio de Janeiro, Paraná, Minas Gerais and Rio Grande do Sul.
\end{abstract}

\section{Introdução}

Fitólitos são partículas de sílica hidratada que se formam durante o crescimento da planta, e, que são liberados quando a planta morre e se decompõe. O termo "fitólito", por vezes, denominado silicofitólitos ou opala biogênica, possui origem grega e significa literalmente "pedra de planta" (Piperno 1991). De acordo com Piperno (2006), o primeiro trabalho desenvolvido sobre fitólitos foi publicado por Struve no ano de 1835 e constituíram-se objeto de estudos de grande número de botânicos alemães no início do século XX. Porém, esses estudos ficaram a margem da ciência moderna devido a sua morfologia e produção serem insuficientemente compreendidas. Somente a partir da década de 1970, um grupo de arqueobotânicos (Twiss 1969, Rovner 1971) começou a explorar a potencialidade da análise fitolítica nas reconstruções paleoambientais, no entanto, tiveram que reiniciar as pesquisas e entender os complexos processos de formação, acumulação e identificação (Piperno 1991).

Piperno (2006) enumera ao menos quatro fases nas pesquisas sobre fitólitos:

I) Fase exploratória - compreendida desde a descoberta por Struve em 1835 a 1895 com o desenvolvimento das pesquisas realizadas por Ehrenberg (1854) apud Mulholland e Rapp (1992), que forjou o termo "Phytolitharia" e formou o primeiro sistema de classificação;

II) Fase botânica (1895-1936) - momento no qual os fitólitos passaram a ser o objeto de estudo de um grande número de botânicos alemães, em continuação ao trabalho de Ehrenberg (1854) apud Mulholland e Rapp (1992) que desenvolveram estudos sobre a produção, morfologia e taxonomia dos corpos de sílica (Kieselkörper). Porém as pesquisas foram interrompidas pela emergência do regime nazista e a subsequente II Guerra Mundial; 
III) Fase ecológica (1955-1975) - período em que se iniciam as aplicações por ecólogos, pedólogos, agrônomos e botânicos, primeiramente nos Estados Unidos, posteriormente no Reino Unido, Austrália e Rússia. Após o estudo realizado por Rovner (1971) as análises fitolíticas começaram a ser difundidas entre os paleoecólogos.

IV) Desde 1978 vivenciamos o período da aplicação arqueológica e paleoambiental. Os arqueólogos passaram a utilizar os fitólitos como um marcador proxy do registro fóssil das plantas, bem como da domesticação e do ambiente. Nas pesquisas paleoecológicas os fitólitos tem servido como proxies sobre a vegetação passada bem como uma poderosa ferramenta complementar aos estudos palinológicos e aqueles envolvendo isótopos estáveis do C da matéria orgânica do solo.

\section{Formação e aplicabilidade dos fitólitos}

O processo de produção dos fitólitos inicia-se quando a sílica dissolvida presente na solução do solo, conhecida como ácido monossílico $\left(\mathrm{H}_{4} \mathrm{SiO}_{4}\right)$ é absorvida pelo sistema radicular e depositada nos espaços intracelulares, paredes celulares e lumina em qualquer órgão durante o crescimento dos vegetais. No entanto, nas estruturas aéreas, como folhas, frutas e brácteas a presença de fitólitos é mais comum que em órgãos subterrâneos (Piperno 1991, Twiss 1969).

Existem ao menos dois mecanismos na acumulação de sílica sólida e produção de fitólitos em vegetais. O primeiro é ativo, que por sua vez, é controlado pela planta por meio dos mecanismos genéticos e fisiológicos. O segundo é passivo e está relacionado às condições climáticas locais e o ambiente de crescimento da planta. Porém, em muitas espécies os dois mecanismos são atuantes (Piperno, 2006) gerando fitólitos com uma grande variedade de tamanhos e formas.

Mesmo após a morte do vegetal os fitólitos não são destruídos e são depositados em solos ou sedimentos. Por serem materiais inorgânicos, compostos por sílica, preservam-se por longos períodos de tempo, constituindo um dos fósseis mais duráveis de plantas terrestres, sendo sua análise, uma importante ferramenta para estudos de reconstrução paleoambiental (Piperno 2006).

As razões da produção de fitólitos pelas plantas ainda são poucos conhecidas, porém Madella (2009) salienta ao menos quatro possibilidades: i) oferecer suporte mecânico para as células; ii) dar suporte aos órgãos e estruturas da planta; iii) proteger a planta de herbívoros e parasitas e iv) neutralizar ânions e cátions nocivos ao desenvolvimento das plantas.

Os estágios de desenvolvimento de fitólitos nas plantas estão relacionados a um grande número de fatores, incluindo ambiente climático de crescimento, tipo de solo, a quantidade de água no solo, idade da planta e, o mais importante, que é a afinidade taxonômica para a produção de fitólitos (Madella, 2009). A produção de fitólitos possui uma regularidade maior em monocotiledôneas, dicotiledôneas e pteridófitas (Piperno 2006).

Os fitólitos, devido às suas características intrínsecas (ex: produção relativa às condições fisiológicas e ambientais, resistência a dissolução e ubiquidade) pode constituir um importante indicador do ambiente de formação e dos processos de pedogênese, bem como tafonômicos (Osterrieth et al. 2009). Existe um enorme potencial para a análise fitolítica nos diversos campos do conhecimento (arqueologia, agronomia, paleobotânica, paleoecologia, pedologia, paleoetnobotânica), em virtude da sua utilidade para a reconstrução da vegetação pretérita, como complemento aos estudos dos isótopos estáveis de $\mathrm{C}$ e $\mathrm{N}$ e da paleopalinologia, quando a preservação de palinomorfos (p.ex. esporos e pólen) é escassa.

Os vegetais apresentam uma enorme multiplicidade e redundância na produção dos fitólitos. Uma única forma pode aparecer em diversas espécies, raramente uma forma em especifico pode ser relacionada a um táxon, nesse sentido a assembleia fitolítica deve sempre ser considerada e cuidadosamente analisada. As assembleias fósseis de fitólitos devem ser sempre acompanhadas da comparação com assembleias modernas, coletadas nos horizontes superiores do solo ou em superfícies de erosão (Bremond et al. 2005). Na tabela a seguir são apresentados os principais morfotipos de fitólitos produzidos pelos vegetais (Tab. 1):

Algumas famílias de plantas apresentam maior capacidade para a produção e acumulação de corpos silicosos (Poaceae, Cyperaceae, Ulmaceae, Fabaceae, Curcubitaceae, Asteraceae). Entretanto, nessas famílias pode haver espécies produtoras e não produtoras. Os fitólitos apresentam produção e acumulação in situ, no entanto, quando submetido ao fogo, vento e atividade hídrica podem percorrer distâncias consideráveis (Rapp e Mulholland,1992). As Poaceae (gramíneas) são conhecidas como grandes produtoras de fitólitos, cerca de 20x superio- 
Estágio Atual do Conhecimento sobre Fitólitos no Brasi

Tabela 1. Principais formas e características dos fitólitos.

\begin{tabular}{|c|c|c|c|}
\hline Tipo & Táxon & Ambiente & $\begin{array}{c}\text { Representação } \\
\text { Madella et al. (2005) }\end{array}$ \\
\hline $\begin{array}{c}\text { Bilobate short cell } \\
\quad(\text { dumbbell) } \\
\text { (Barboni et al. 1999) }\end{array}$ & $\begin{array}{c}\text { Gramíneas } \\
\text { sobretudo Panicoideae } \\
\text { alta } \mathrm{C}_{4} \text {, também algumas } \\
\text { Panicoideae } \mathrm{C}_{3} \text {; Chloridoideae, } \\
\text { Arundinoideae e Bambusoideae }\end{array}$ & $\begin{array}{l}\text { Quente úmido } \\
\text { Áreas à sombra, sob } \\
\text { o dossel de florestas } \\
\text { tropicais }\end{array}$ & \\
\hline $\begin{array}{c}\text { Saddle } \\
\text { (Barboni et al. 1999) }\end{array}$ & $\begin{array}{l}\text { sobretudo } \\
\mathrm{C}_{4} ; \text { algumas } \text { Chloridoideas } \\
\text { Arundinoideae baixas } \mathrm{C}_{3}\end{array}$ & $\begin{array}{l}\text { Regiões secas } \\
\text { de baixa latitude } \\
\text { e altitude ou } \\
\text { condições edáficas }\end{array}$ & \\
\hline $\begin{array}{c}\text { Rondel } \\
\text { (conical, circular) } \\
\text { (Barboni et al. 1999) }\end{array}$ & $\begin{array}{l}\text { Gramíneas } \\
\text { sobretudo Pooideae } \mathrm{C}_{3} \text {, } \\
\text { também Bambusoideae } \mathrm{C}_{3}\end{array}$ & $\begin{array}{l}\text { Regiões } \\
\text { temperadas, frias e } \\
\text { altas elevações } \\
\text { intertropicais }\end{array}$ & \\
\hline $\begin{array}{c}\text { Elongate echinate long } \\
\text { cell } \\
\text { (elongate spiny) } \\
\text { (Barboni et al. 1999) }\end{array}$ & long cells de todas as gramíneas & & \\
\hline $\begin{array}{l}\text { Elongate psilate } \\
\text { (elongate smooth) }\end{array}$ & long cells de todas as gramíneas & & \\
\hline Cylindrical polylobate & $\begin{array}{l}\text { predominam nas Panicoideae } \\
\left(\mathrm{C}_{4} \text { e } \mathrm{C}_{3}\right)\end{array}$ & $\begin{array}{l}\text { Clima quente } \\
\text { úmido }\end{array}$ & \\
\hline $\begin{array}{l}\text { Trapeziform short-cell } \\
\text { (rectangular) }\end{array}$ & $\frac{\text { Gramíneas }}{\text { Pooideae }}$ & $\begin{array}{l}\text { Regiões } \\
\text { temperadas, frias } \\
\text { e altas elevações } \\
\text { intertropicais }\end{array}$ & \\
\hline $\begin{array}{l}\text { Acicular hair cell } \\
\text { (point-shaped) }\end{array}$ & $\begin{array}{l}\text { Gramíneas } \\
\text { (micro-hair ou prickels de todas } \\
\text { as epidermes); também nas } \\
\text { Palmae, sementes de outras } \\
\text { plantas }\end{array}$ & & \\
\hline $\begin{array}{l}\text { Bulliform cell } \\
\text { Cuneiform (fan- } \\
\text { shaped) } \\
\text { Parallelepipedal }\end{array}$ & $\begin{array}{c}\text { Gramíneas } \\
\text { (células buliformes de todas as } \\
\text { epidermes) }\end{array}$ & & \\
\hline $\begin{array}{l}\text { Globular granulate } \\
\text { (spherical rugose) }\end{array}$ & $\begin{array}{c}\text { Dicotiledôneas lenhosas } \\
\text { (troncos de árvores e arbustos } \\
\text { tropicais) }\end{array}$ & & \\
\hline $\begin{array}{l}\text { Globular psilate } \\
\text { (spherical smooth) }\end{array}$ & $\begin{array}{l}\text { Dicotiledôneas } \\
\text { (epidermes de folhas e } \\
\text { parênquima) } \\
\text { Gramíneas } \\
\text { (raízes e sementes) }\end{array}$ & & \\
\hline $\begin{array}{l}\text { Globular echinate } \\
\text { (Crenate spherical) }\end{array}$ & Troncos e folhas das Arecaceae & & \\
\hline
\end{tabular}


res as dicotiledôneas lenhosas, podendo atingir de $1 \%$ a $5 \%$ de Si no peso seco (Webb e Longstaffe 2000).

A utilização dos fitólitos como ferramenta de reconstrução paleoambiental depende impreterivelmente das condições da sua estabilidade em solos e em sedimen-

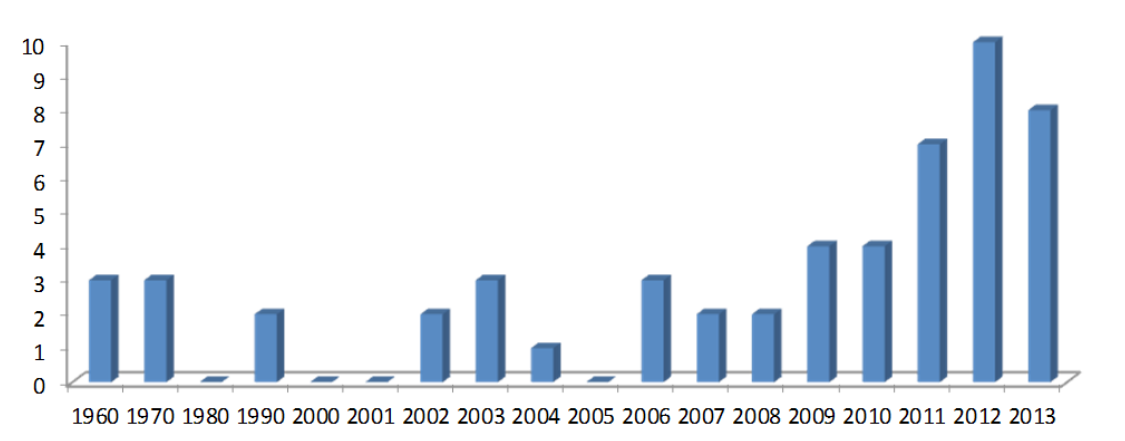

tos. Há amplas evidências de que a preservação dos fitólitos está relacionada a diversos fatores: a) $\mathrm{pH}$ do solo (valores acima de $\mathrm{pH} 9$ que tendem a acelerar o processo de dissolução, principalmente em ambientes quentes e úmidos); b) tipo de fitólito (os fitólitos produzidos nas células são mais duráveis que os produzidos nas paredes celulares); c) elementos como $\mathrm{Fe}$ e $\mathrm{Al}$ quando absorvidos juntamente com a sílica parece proteger os fitólitos contra a dissolução; d) condições favoráveis de preservação no ambiente de deposição e e) superfície do fitólitos, as formas que apresentam maior área são mais atacadas pela dissolução (Piperno 2006).

Diante do exposto a pesquisa analisou a produção científica sobre fitólitos no Brasil e os principais obstáculos e as perspectivas para o desenvolvimento dos estudos nesse campo do conhecimento.

\section{Materiais e métodos}

Para o levantamento dos trabalhos (teses, dissertações, artigos em periódicos, artigos em eventos e resumos expandidos) foi utilizado o buscador de periódicos da CAPES (www.periodicos.capes.gov. br), Google Scholar ${ }^{\circledR}$ (www.scholar.google.com. br), o acesso ao currículo Lattes (www.lattes.cnpq.br) dos principais pesquisadores sobre o tema no Brasil e solicitação por e-mail aos mesmos para o envio dos trabalhos. Os trabalhos foram divididos entre: 1) pesquisas de reconhecimentos dos padrões de produção de fitólitos em plantas modernas e 2) aplicação de fitólitos como ferramenta de reconstrução paleoambiental. Para a espacialização geográfica das pesquisas foi utilizado o programa CorelDraw x5®.

\section{Resultados e discussão}

Os estudos sobre fitólitos em plantas atuais, bem como o seu uso como ferramenta de recons-

trução paleoambiental ainda são incipientes no Brasil. Nesse sentido, o gráfico seguinte (Fig. 1) evidencia o número de publicações realizadas desde meados da década de 1960 até junho de 2013, destacando os estudos sobre morfotipos extraídos de táxons de plantas atuais, com intuito de estabelecer uma coleção de referência de assembleias fitolíticas modernas, assim como sua aplicação como instrumento nos trabalhos de reconstruções paleoambientais. Nota-se que os estudos pioneiros, se iniciaram ainda na década de 1960, com um total de três produções, esse foi o mesmo total ao longo da década de 1970, no entanto, nas décadas seguintes a produção científica com essa temática tornou-se esparsa, adquirindo maior regularidade de publicação na última década, chegando a totalizar 10 trabalhos sobre fitólitos no ano de 2012, com maior número de publicações referentes a sua utilização como indicador "proxy" (6 trabalhos).

A seguir são detalhadas as principais pesquisas que versam tanto sobre os estudos de classificação e morfologia quanto os estudos que fazem uso desse aparato como recurso (dado "proxy") para a reconstrução paleoambiental.

1) Estudos sobre morfologia de fitólitos em plantas atuais

Dentre os trabalhos de identificação de fitólitos atuais no Brasil, destaca-se a pesquisa pioneira de Sendulsky e Labouriau (1966), na qual realizaram um estudo preliminar de 55 espécies de gramíneas do Cerrado com o objetivo de agregar maiores informações sobre a formação dos fitólitos que pudessem ser utilizados na taxonomia e na diferenciação da vegetação de Cerrado. As gramíneas do Cerrado apresentaram grande abundância e boa variedade de corpos silicosos, com trechos da epiderme das plantas inteiramente silicificados, inclusive as células dos estômatos.

Ainda na década de 1960, Cavalcante (1968) 
realizou a descrição dos corpos silicosos das gramíneas amazônicas, tendo como foco a subfamília Panicoideae. No trabalho, o autor inclui as tribos Melinideae, Andropogoneae e Tripsaceae pertencentes à flora Amazônica, identificando grupos distintos de morfologias dos fitólitos, ao distribuir os corpos silicosos em três grupos que variam quanto a sua forma.

Posteriormente, em trabalhos contíguos, Campos e Labouriau (1969) estudaram os fitólitos produzidos por dez espécies de gramíneas ocorrentes em Cerrados, como parte de um levantamento morfológico de corpos silicosos característicos de plantas do Brasil, cuja finalidade básica consiste na obtenção de informações qualitativas primordiais para a investigação das oscilações de fronteiras entre Cerrados e demais formações botânicas adjacentes por meio de fitólitos. Para o estudo dos corpos silicosos, os autores propõem o aperfeiçoamento da técnica de preparação, mediante a extração preliminar do material alcalino antes da incineração, de modo a evitar fusão alcalina de sílica e, ainda, pela realização de um ensaio em branco. As semelhanças e diferenças que se observam entre as espécies estudadas pelos autores e o estudo preliminar que o precedeu (Sendulsky e Labouriau 1966) já permitem entrever o significado taxonômico dos corpos silicosos.

Dando continuidade aos trabalhos atinentes ao levantamento das formas dos corpos silicosos característicos de gramíneas do Cerrado, Silva e Labouriau (1970) realizaram a extração do resíduo silicoso de amostras provenientes de material herbário, sendo que o mesmo foi montado em lâminas e as formas ocorrentes desenhadas à câmara-clara. As descrições e comparações objetivavam contribuir para a identificação de um sítio de cerrado a partir dos fitólitos produzidos por sua flora.

Söndahl e Labouriau (1970) investigaram as formas dos fitólitos de dez espécies do Cerrado, em continuação dos trabalhos de Sendulsky e Labouriau (1966), Campos e Labouriau (1969) e de Silva e Labouriau (1970), acrescentando as dificuldades encontradas para a realização da pesquisa na época, como instabilidade das designações taxonômicas das gramíneas dos Cerrados; pobreza das coleções agrostológicas de herbários brasileiros e a lacuna nas informações fitossociológicas sobre os Cerrados.

O último artigo de levantamento dos corpos silicosos de gramíneas dos Cerrados foi produzido por Figueiredo e Handro (1971). Neste trabalho foi realizado o levantamento dos corpos silicosos de
12 espécies de gramíneas dos gêneros Aristida sp., Cenchrus sp., Eleusine sp., Eragrostis sp., Ichnanthus sp., Olyra, Paspalum sp., Pennisetum sp., Raddiella sp. e Rhynchelytrum sp.

As pesquisas de identificação e classificação, no entanto, foram cessadas nas décadas subquentes, sendo retomadas apenas na primeira década do século XXI com o trabalho de Lima \& Medeanic (2007) ao estudar os fitólitos de gramíneas que crescem em ambientes costeiros no extremo Sul do Brasil. Foram analisados os morfotipos de fitólitos nas espécies Spartina ciliata Drong. e Panicum racemosum (P. Beauv.) Spreng, com ampla distribuição nas dunas da planície costeira do Rio Grande do Sul.

Da mesma forma, Medeanic et al. (2008) realizaram a descrição morfológica dos fitólitos de sete espécies de gramíneas atuais, abundantes nas dunas do extremo sul da planície costeira do Rio Grande do Sul. Os resultados assinalam a grande variedade dos fitólitos associados a esses vegetais e as características morfológicas específicas de cada espécie. É importante salientar que a pesquisa teve em vista a confecção de um guia de referência, ausente até aquele momento, de fitólitos de plantas de dunas atuais a fim de aplicá-los em futuros estudos dos fitólitos preservados em sedimentos do Quaternário. Em trabalho subsequente, Medeanic et al. (2009) com intuito de contribuir para a ampliação do banco de dados sobre fitólitos em plantas de dunas atuais, procederam na descrição dos tipos morfológicos de fitólitos em Androtrichum trigynum (Spreng.) Pfeiffer. Assim, alguns fitólitos encontrados nos sedimentos holocênicos lagunares da planície costeira do Rio Grande do Sul foram comparados com os fitólitos descritos para essa espécie.

Costa et al. (2010) estudaram a estabilidade da sílica biogênica extraída do capim Jaraguá (Hyparrhenia rufa (Ness) Stapf) em solução de hidróxido de sódio $(\mathrm{NaOH})$. Os autores concluíram que existe uma relação direta entre a composição química e a estabilidade dos fitólitos. Uma vez que Jaraguá possui concentrações consideráveis de $\mathrm{Si}, \mathrm{Al}, \mathrm{Fe}$, $\mathrm{Mg}$ e $\mathrm{P}$ e concentrações menores de $\mathrm{Cu}, \mathrm{Cd}$ e $\mathrm{Zn}$. A solução foi mais ativa nos fitólitos maiores, deferindo entre as formas e tamanhos dos mesmos, e tecidos silificados se dissolveram juntamente com os halteres.

Estudos mais recentes dedicados ao reconhecimento de morfotipos de fitólitos em táxons de plantas atuais podem ser constatados em Rasbold et al. (2010), ao realizarem a avaliação das formas de fitólitos presentes na espécie Cyperus giganteus 
Vahl. (Cyperaceae), a qual ocorre em extensas áreas do Pantanal Mato-Grossense, o que permite classificá-la como um indicador natural das atuais de condições ambientais. Os autores, ao analisarem detalhadamente os morfotipos presentes em cada estrutura vegetal do espécime, concluiram que a maior quantidade e diversidade de fitólitos encontrados ocorrem na espigueta, predominando as formas de "Trapeziform sinuate", "Trapeziform polylobate" e "Elongate", enquanto as menores quantidades e diversidades de fitólitos verificaram-se no fruto, bainha e rizoma. Por sua vez, Rasbold et al. (2011) estudaram a produção de fitólitos pela espécie Butia paraguayensis (Barb. Rodr.) L. H. Bailey (Arecaceae), que está na lista vermelha de plantas ameaçadas de extinção no Paraná e representa uma das espécies características da vegetação de cerrado em Campo Mourão. A caracterização dos tipos morfológicos apontou a predominância de formas "Globular echinate", sendo encontrado em todas as estruturas da planta e em maior quantidade, portanto caracterizados como padrão para a família Arecaceae. Costa et al. (2011) realizou uma análise aprofundada da formação dos corpos silicosos em plantas das subfamílias de Podostemaceae.

Calegari et al. (2011) no trabalho publicado no encontro da ABEQUA (Associação Brasileira de Estudos do Quaternário) faz uma primeira aproximação dos principais morfotipos de fitólitos presentes em um fragmento de Floresta Ombrófila Mista e Campo presente no Sudoeste do Estado do Paraná, tema posteriormente aprofundado pela dissertação de Raitz (2012).

Buscando expandir o acervo de referências de fitólitos característicos de plantas pertencentes à família Arecaceae, Monteiro et al. (2012) analisaram a morfologia de fitólitos de duas espécies ocorrentes no Bioma Mata Atlântica: Bactris setosa Mart. e Geonoma schottiana Mart. $O$ estudo evidenciou que $B$. setosa apresenta de maneira predominante o fitólito "Conical echinate", enquanto que em G. schottiana ocorre de forma abundante o tipo "Globular echinate". Tais tipologias fitolíticas apresentam-se em grande quantidade nas três estruturas vegetais analisadas pelos autores, isto é, na bráctea, folíolo e ráquila, evidenciando a grande produção de fitólitos representativos em ambas as espécies de palmeiras e a sua importância em futuras reconstruções paleoambientais, possibilitando a identificação dessas formas preservadas em sedimentos a partir das comparações com assembleias fitolíticas modernas.

Com objetivo de expandir as informações sobre os fitólitos em gramíneas brasileiras, em especial da subfamília Chloridoideae, Rasbold et al. (2012) fizeram o levantamento dos corpos silicosos de três espécies, Chloris elata Desv., Chlrois gayana Kunth e Tripogon spicatus (Ness) Ekman, que se desenvolvem em diversos domínios fitogeográficos brasileiros. Nas três espécies analisadas houve a predominância do tipo "Saddle" $(87,1 \%)$ e do tipo "Bilobate" $(6,8 \%)$, o estudo foi acompanhado da análise isotópica $\left(\delta^{13} \mathrm{C}\right)$ indicando serem plantas de ciclo fotossintético $\mathrm{C}_{4}$.

Em consonância com tais estudos, Raitz (2012) desenvolveu sua dissertação de mestrado pautada na elaboração de uma coleção de referência de fitólitos da flora do Sudoeste do estado do Paraná, como subsídios para estudos paleoambientais. Foram consideradas duas principais fitofisionomias (Floresta Ombrófila Mista e Campo), cujo levantamento florístico indicou maior representatividade de espécies das famílias Lauraceae, Myrtaceae, Poaceae, Pteridaceae e Fabaceae para a formação vegetal caracterizada pela Floresta Ombrófila Mista, e elevada representatividade de espécies das famílias Poaceae, Asterceae, Cyperaceae e Lauraceae para a vegetação do Campo. A pesquisa objetivou suprir a carência de informações acerca da produção de fitólitos pela vegetação do Brasil, compondo um referencial importante sobre morfotipos fitolíticos, principalmente para a região Sudoeste do Paraná, onde os estudos ainda são incipientes, bem como demonstrou o potencial da análise de fitólitos para a reconstrução paleoecológica na região Sul do Brasil, visto a possibilidade de diferenciar unidades de vegetação dominada por Campo e/ou Floresta por meio de suas assinaturas fitolíticas.

Diante do exposto, nota-se a relevância dos trabalhos sobre morfologia de fitólitos, uma vez que o estabelecimento de assembleias fitolíticas, extraí-das de plantas modernas, pode auxiliar estudos que versam sobre reconstruções paleoambientais, sendo um referencial para a identificação taxonômica dos morfotipos encontrados em sedimentos/solos, podendo chegar à categoria de família, e por vezes de gênero.

2) Fitólitos como instrumento de reconstrução paleoambiental

O emprego dos fitólitos como "proxy" na interpretação paleoambiental, teve início no Brasil com o trabalho de Piperno e Becker (1996), que analisaram fitólitos em consonância com análise antracológica em solos no ambiente de "Terra firme" na Amazônia central. Os autores evidenciaram que a 
vegetação da área foi instável durante o Holoceno, com presença de incêndios entre 1795 e 550 anos AP. Não obstante, Alexandre et al. (1999) estudaram assembleias fitolíticas presentes em latossolo no município de Salitre, Minas Gerais, e os dados obtidos descreveram uma fase com presença de Cerrado entre 5500 e $4500 \mathrm{cal}$. AP. seguido por dois momentos de desenvolvimento de florestas (4000-3000 cal AP. e após 970 cal AP.). Esses foram os únicos trabalhos publicados de reconstrução paleoambiental no Brasil com uso de fitólitos em toda a década de 1990.

Já na última década houve um incremento nas pesquisas e um volume consistente de trabalhos têm sido publicados. Borba-Roschel et al. (2006) apresentaram discussão sobre os dados obtidos no bioma Cerrado, município de Uberaba - MG, comparando os fitólitos extraídos de uma turfeira com assembleias fitolíticas de plantas dominantes (Cyperaceae e Poaceae). Os autores observaram a diminuição de fitólitos de Cyperaceae conforme a profundidade e relacionaram com as fases de hidratação e desidratação do material.

No mesmo ano, Paula e Silva (2006) observaram a morfologia e quantificaram as opalas biogênicas em dois locais de cimeira com Latossolo Vermelho textura média e argilosa sob Cerrado e dois locais em encosta com solos Glei, pouco húmico, sob Cerradões de Uberlândia, comparando-se os dados com a quantidade de silício do solo. Em todas as profundidades estudadas, verificou-se que tanto os latossolos como o glei pouco húmico continham quantidades maiores de opala biogênica no silte que na areia muito fina, evidenciando ainda que tais quantidades de silicofitólitos diminuem com a profundidade, ao passo que a quantidade de silício assimilável aumenta, o que pode estar associado provavelmente a sua facilidade de ser carreado verticalmente nos processos de lixiviação. Nesse sentido, a pesquisa objetivou expandir o estudo das opalas em solos, visto que tem se mostrado bastante útil para o entendimento de relações como disponibilidade de silício para as plantas, pedologia (detecção de descontinuidades litológicas) e reconstituição de paleoambientes. No mapa a seguir (Fig. 2) é apresentada a distribuição dos trabalhos sobre fitólitos no território nacional.

No ano de 2007, ressalta-se a utilização dos fitólitos em estudos arqueológicos, conforme pesquisa desenvolvida por Wesolowski et al. (2007), que apresentaram resultados referentes a recuperação e análise de micro-vestígios vegetais retidos em cálculos dentários de grupos de pescadores-coletores do litoral sul do Brasil. Assim, por meio de dissolução química de cálculos dentários, foi evidenciado o consumo de alimentos amiláceos em

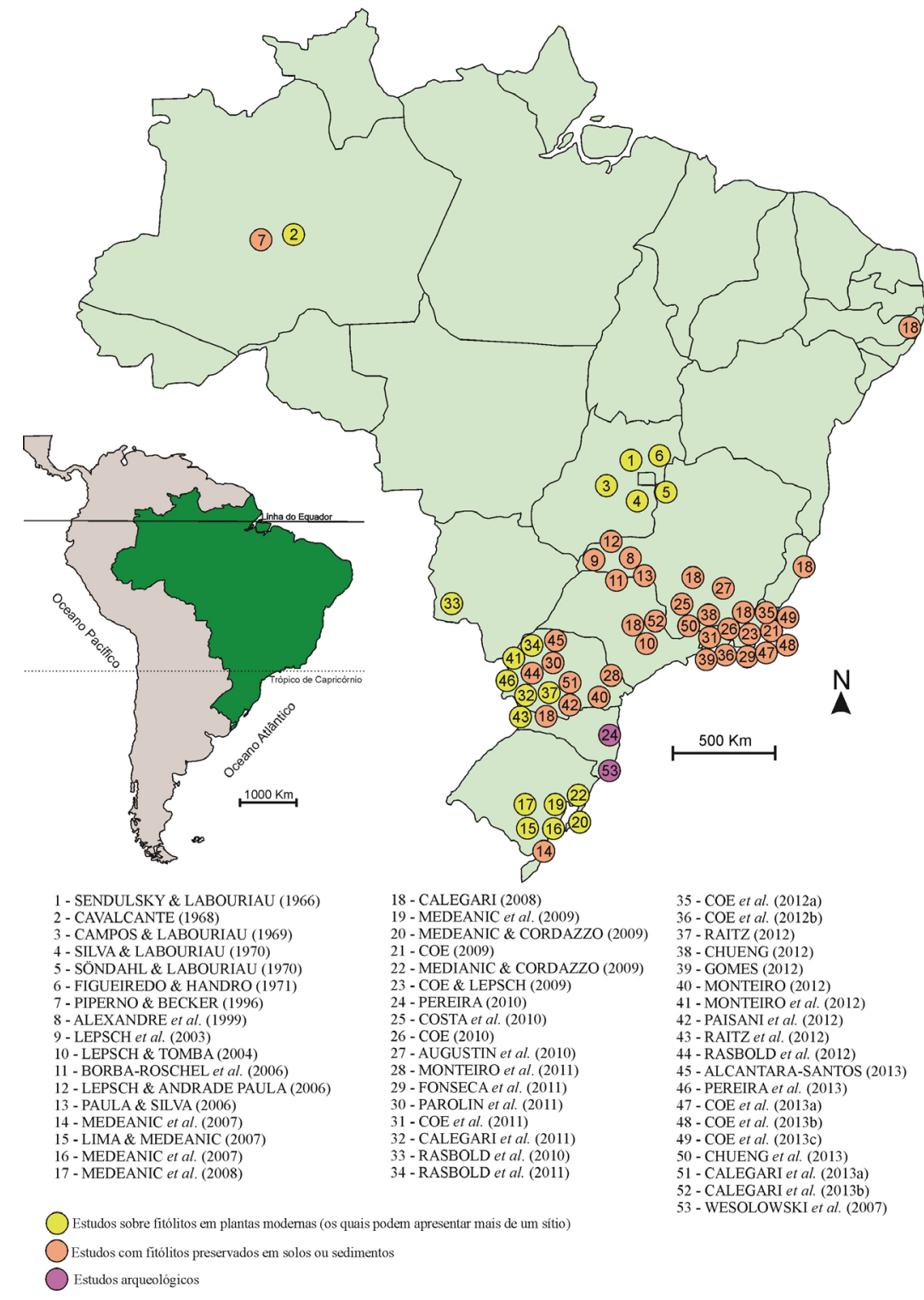

Figura 2. Distribuição dos trabalhos sobre fitólitos no território nacional 
todas as séries esqueléticas observadas, constatando independência entre dieta com aporte de produtos vegetais e utilização de cerâmica.

Recentemente, Calegari (2008) desenvolveu sua tese de doutorado sobre do horizonte A húmico em Latossolos em distintas regiões do Brasil, com o uso dos fitólitos e técnicas isotópicas $\left(\delta^{13} \mathrm{C}\right)$ como marcadores das condições paleoambientais de origem. Para tanto, três grupos de Latossolos com A húmico foram definidos: G1 - Latossolos Brunos e Vermelhos localizados na região Sul (Guarapuava/PR); G2 - Latossolos Vermelho-Amarelos e Amarelos encontrados de forma predominante na região Sudeste (Machado/MG); G3 - Latossolos Vermelho-Amarelos e Amarelos das regiões Sudeste (Campinas/SP) e Nordeste (Pau D'alho/ $\mathrm{PE}$ ), com horizonte húmico mais espesso. Os resultados demonstraram que o horizonte A húmico se formou sob vegetação menos densa que a atual nas regiões Sudeste e Nordeste, conforme indicado pela análise fitolítica e valor $\delta^{13} \mathrm{C}$, que apontou mistura de plantas de ciclo $\mathrm{C}_{3}$ e $\mathrm{C}_{4}(\sim-22 \%$ o), com predomínio de plantas $\mathrm{C}_{3}$, enquanto que na região Sul houve o desenvolvimento de vegetação mais aberta com predomínio de plantas $\mathrm{C}_{4}(\sim-16 \%$ o), indicando assim, clima mais seco entre o Holoceno inferior e médio. No Holoceno superior, constatou-se a expansão da vegetação de floresta em decorrência de um empobrecimento isotópico ( - 25\%o), inferindo-se clima mais úmido e quente, semelhante ao atual, nas regiões Sudeste e Nordeste, e mais úmido e frio na região Sul.

Em sua tese de doutoramento, Coe (2009) apresentou estudo referente à evolução da vegetação xeromórfica na região de Búzios/Cabo Frio - RJ, a partir dos fitólitos extraídos de amostras coletadas em solos da região. A região de Búzios/ Cabo Frio é considerada como um "enclave fitogeográfico" de vegetação xeromórfica com fisionomia similar à da caatinga do semiárido nordestino, apresentando um clima mais seco que o restante do litoral fluminense. Os resultados permitiram identificar mudanças na densidade de cobertura arbórea, não se registrando grandes variações no tipo de formação vegetal desde os últimos $\sim 13 \mathrm{ka}$ cal AP., o que sugere que a vegetação foi sempre de tipo pouco arbórea, caracterizada pela presença de flora xeromórfica, nunca atingindo a densidade arbórea típica de florestas úmidas durante o intervalo de tempo compreendido no estudo.

Pereira (2010) desenvolveu notável estudo com enfoque para os fitólitos presentes em frag- mentos de carvão, denotando sua relevância como ferramenta aplicada à pesquisa arqueológica. Dessa forma, procedeu-se a identificação e observação de fitólitos a partir de fragmentos de carvão obtidos no sítio Garopaba IV situado no litoral de Santa Catarina, propondo uma nova abordagem sobre estes proeminentes achados arqueológicos. O trabalho se demonstrou inovador e eficaz, uma vez que a presença de carvão, como se pôde constatar, é um traço marcante em sítios arqueológicos, sendo sua análise não somente para fins antracológicos. Os resultados apontam a viabilidade da análise fitolítica por meio da utilização de fragmentos de carvão, evidenciando a fácil identificação morfológica bem como a coloração dos fitólitos ocorrentes, o que pode ajudar a reconstruir o modo de vida e a cultura de determinado grupo humano, constituindo assim, boa ferramenta nos estudos arqueológicos.

Em trabalho posterior, Coe et al. (2011) dedicaram-se ao estudo sobre gênese de solos e mudanças ambientais na bacia do rio São João - RJ, identificadas pela análise fitolítica. Amostras de quatro perfis de solo foram analisadas, sendo um Glei, um Neossolo Flúvico, um Argissolo e um Planossolo. As análises evidenciaram a presença de assembleias fitolíticas em todos os horizontes desses solos, contudo demonstraram variações no teor de fitólitos e nos tipos ocorrentes de acordo com a origem do material onde procedeu a pedogênese. Assim, foi estabelecido para os dois perfis de solo desenvolvidos a partir de material de origem sedimentar (glei e neossoloflúvico) a incidência de fitólitos muito misturados, apresentando quantidade semelhante em todos os horizontes, enquanto que entre os solos desenvolvidos a partir de material parental. Verificou-se que no argissolo o teor em fitólitos diminui com a profundidade, conforme padrão normal de distribuição, não ocorrendo o mesmo para o planossolo, já que este não apresenta o padrão normal de diminuição com a profundidade, pois os fitólitos são carreados dos horizontes superficiais vindo a concentrar-se no Horizonte textural. Nestes dois perfis de solo foram constatados tipos predominantes de fitólitos.

Monteiro et al. (2011) traçaram os primeiros esboços sobre as condições paleoambientais durante o Holoceno Tardio na região dos Campos Gerais, no Estado do Paraná, a partir da análise de fitólitos presentes em sedimentos turfosos. A pesquisa revelou a ocorrência de oscilações climáticas no período, registrando fases mais frias e secas que as atuais em 3.220 anos AP, passando para mais 
quentes e úmidas em 2.770 anos AP, com retorno para condições mais secas e frias em 1.340 anos AP. Essas interpretações estão de acordo com outros trabalhados que apontam semelhantes condições climáticas durante o Holoceno. Cabe salientar da mesma forma, a contribuição dos estudos desenvolvidos por Parolin et al. (2011), que fizeram os primeiros apontamentos sobre mudanças ambientais em Campo Mourão - PR utilizando por base a análise das assembleias fitolíticas e análises de $\delta^{13} \mathrm{C}$. Os autores constaram que não há incidência de vegetação densa na região desde o Pleistoceno Tardio associado a uma condição mais seca que a atual desde os últimos $\sim 25.000$ anos.

Investigações mais recentes foram realizadas por Gomes (2012) que apresentou discussão envolvendo a análise de fitólitos para a compreensão da gênese e evolução de solos na bacia do rio São João - RJ. Para tanto, foram coletadas amostras de cindo perfis de solos da região, sendo dois de origem aluvial e três de origem eluvial conforme indicado pelos resultados das análises fitolíticas, cabendo à ressalva de que o "proxy" em questão apresentou limitações para reconstituições da vegetação e inferências climáticas em solos de origem aluvial, haja vista a mistura de materiais de aporte do rio, não verificando-se o mesmo para os solos desenvolvidos a partir de material in situ, onde os fitólitos se mostraram bons indicadores de mudanças ambientais.

Chueng (2012) realizou estudo na região do Espinhaço Meridional, em Minas Gerais, inferindo variações climáticas e da cobertura vegetal por meio de análises fitolíticas e isotópicas, auxiliando dessa forma na compreensão dos processos geomorfológicos que levaram à formação da sequência alúvio-colovial na região. Nos dois perfis de solos analisados foi possível identificar sequências deposicionais desenvolvidas concomitantemente no tempo, no entanto com processos de acumulação e intensidade ocorrendo de formas diferentes. Os resultados sugerem a atuação intensa de processos erosivos na área de estudo, visto que em ambos os perfis, mesmo nos horizontes mais superficiais, e em praticamente todas as assembleias modernas coletadas nas proximidades, os fitólitos se apresentaram profundamente alterados, evidenciando o predomínio de fitólitos grandes ("blocky", "bulliform" poliédricos, "elongate"), já que estes são mais resistentes à erosão, porém ainda assim mostraram-se muito alterados, ocorrendo baixas proporções ou inexistência de fitólitos pequenos ("short cells"), que são mais frágeis. Pôde-se constatar que nos horizontes mais superficiais, os índices fitolíticos são característicos de vegetação aberta, sendo que no P1 a densidade arbórea atual é um pouco maior que em P2, embora ambos apresentem valores típicos de formações de cerrado, com predomínio de gramíneas, indicando assim um ambiente mais seco.

Coe et al. (2012) citou exemplo de três casos de utilização dos indicadores fitólitos e isótopos de carbono em estudos de reconstituições da vegetação e inferências de paleoclimas, compreendendo áreas do Estado do Rio de Janeiro e Minas Gerais. Tais estudos reforçam a importância dos fitólitos nas reconstruções paleoambientais, uma vez que, associado a outros "proxy" (análise "multiproxy"), permitem compreender a evolução da paisagem e as mudanças ambientais de uma determinada região ao longo de um espaço de tempo geológico.

As contribuições concernentes a utilização de fitólitos como indicador "proxy" podem ser verificadas, igualmente, no trabalho de Monteiro (2012) ao estudar os fitólitos em sedimentos turfosos nos Campos Gerais do Estado do Paraná para inferir paleoambientes. Cabe a ressalva de que em estudo precedente (Monteiro et al. 2011) a autora já havia apresentado os primeiros apontamentos sobre as condições paleoambientais na área, ampliando tais discussões em seu trabalho de conclusão de curso. Na presente pesquisa, Monteiro (2012) identificou quatro fases ambientais distintas na região, alternadas por fases mais frias e secas em 3.220 e 2.770 anos AP, com ocorrência de alguns intervalos úmidos associados às cheias do rio Tibagi; fase mais quente e úmida com o aparecimento de fitólitos de Araucaria a $1.340 \pm 80$ anos $\mathrm{AP}$, com retorno das condições mais secas e frias e posterior fase caracterizada por condições climáticas quente e úmida mais próximas as atuais com episódios de cheias indicadas pela presença de espícula de esponja. O trabalho corrobora informações apresentadas anteriormente pela mesma autora, apontando para períodos de oscilações climáticas desde 3.220 anos até o presente para a região dos Campos Gerais - Ponta Grossa, que registrou cobertura de gramíneas desde o período de tempo analisado, fato corroborado pelos valores de $\delta^{13} \mathrm{C}$ que indicaram a predominância de plantas de ciclo fotossintético $\mathrm{C}_{4}$.

Recentemente, Alcantara-Santos (2013) realizou a reconstituição paleogeográfica e paleoambiental do baixo curso do rio Ivaí - PR, tendo como foco a recuperação, identificação e quantificação de fitólitos, além de outros indicadores, presentes em 
um perfil de solo da Formação Caiuá denominado de Trincheira Reserva (TR), bem como em sedimentos do Terraço Ivaí (TI), ambos localizados na região de Douradina - PR. Os dados apontaram mudanças na paisagem em três fases distintas para o TI, correspondendo a uma fase de canal ativo datado em 19.900 \pm 2.800 anos (TL), fase de abandono de canal em 13.250 \pm 1.890 anos (TL) com formação de planície aluvial e do Terraço. Já na TR, foi possível reconstituir o ambiente em duas fases, sendo uma caracterizada por condições ambientais ligeiramente mais secas que as atuais, sob o domínio de floresta em 10.195 anos Cal. AP - o que sugere a presença de refúgios florestais no baixo vale do rio Ivaí -, e outra por condições mais úmidas há pelo menos 5.963 anos Cal. AP.

\section{Conclusões}

O trabalho agregou uma compilação de dados acerca da produção científica do uso de fitólitos no Brasil, demonstrando a importância dos estudos com enfoque para a elaboração de uma coleção de referência de morfologias de fitólitos atuais, bem como sua utilização como ferramenta de interpretação paleoambiental e arqueológica. Contatou-se a carência de informações a respeito da produção de fitólitos pela flora brasileira, sendo os estudos nessa área ainda incipientes e pouco desenvolvidos, destacando-se o conhecimento sobre a produção de corpos silicosos por gramíneas dos Cerrados, conforme pesquisas realizadas sobre esse bioma, além de gramíneas de dunas no extremo sul da planície costeira do Rio Grande do Sul, trabalhos esparsos de gramíneas na Amazônia, sobre a Floresta Ombrófila Mista no Sudoeste do Paraná, Pantanal Mato-Grossense, em fragmentos de Cerrado, Caatinga, Pampa, Campo e em espécies do Bioma Mata Atlântica.

A deficiência das publicações com assembleias fitolíticas modernas compromete um maior entendimento das condições paleoambientais e paleoclimáticas com base na análise fitolítica, dada a ausência de um referencial completo dos morfotipos para a identificação taxonômica em sedimentos/solos. Apesar da importância dos fitólitos nas pesquisas arqueológicas, nota-se igualmente a escassez das abordagens, evidenciando-se no presente estudo apenas dois trabalhos, sendo um de fitólitos extraídos de fragmentos de carvão e outro pertinente aos vestígios vegetais em cálculos dentários de grupos sambaquianos. Igualmente observa-se a concentra- ção no Centro-Sul do Brasil, com maior número de publicações nos estados do Rio de Janeiro, Paraná, Rio Grande do Sul e Minas Gerais.

\section{Agradecimentos}

Os autores agradecem aos comentários dos revisores anônimos, ao CNPq (Conselho Nacional de Desenvolvimento Científico e Tecnológico) (proc. 472.496/2011-5), ao convênio com a Fundação Araucária (Proc. 1251/2012) e EMBRAPA Cerrado por facilitar o acesso aos artigos presentes em sua biblioteca. O primeiro e segundo autor agradecem a CAPES (Coordenação de Aperfeiçoamento de Pessoal de Nível Superior) pela concessão de bolsa de doutorado e mestrado, respectivamente, e o terceiro autor agradece a bolsa de produtividade da Fundação Araucária.

\section{Referências}

Alcantara-Santos J.C. 2013. Paleogeografia e paleoambientes do Baixo Curso do rio Ivaí, PR. Maringá: Univ. Est. Maringá. 83p. (Progr. Pós-Grad. Geografia, Dissert. Mestrado).

Alexandre A., Meunier J.-D., Mariotti A., Soubies F. 1999. Late Holocene Phytolith and CarbonIsotope Record from a Latosol at Salitre, SouthCentral Brazil. Quaternary Research, 51:187-194.

Augustin C., Coe H.H.G, Chueng K.F., Vasconcelos A.M.C. 2010. Geomorphic interpretations and climatic conditions in the Upper Pleistocene in Southeast Brazil: contribution of phytoliths. In: Intern. Meet. Phytolith Res., 8, 2010. Abstracts, PaleoResearch Institute (PRI), Colorado, USA.

Barboni D., Bonnefille R., Alexandre A., Meunier J.-D. 1999. Phytoliths as Paleoenvironmental Indicators, West Side Middle Awash Valley, Ethiopia. Palaeogeography, Paleoclimatology, Paleoecology, 152:87-100.

Borba-Roschel M., Alexandre A., Varajão A.F.D.C., Meunier J.-D., Varajão C.A.C., Colin F. 2006. Phytoliths as Indicators of Pedogenesis and $\mathrm{Pa}-$ leoenvironmental Changes in the Brazilian Cerrado. Journal of Geochemical Exploration, 88(1):172176.

Bremond L., Alexandre A., Peyron O., Guiot J. 2005. Grass Water Stress Estimated from Phytoliths in West Africa. Journal of Biogeography, 32:311-327.

Calegari M.R. 2008. Ocorrência e significado paleoambiental do horizonte $A$ húmico em latossolos. Piracicaba: ESALQ. Univ. de São Paulo. 259p. (Progr. Pós-Grad. Agronomia, Tese Dout.).

Calegari M.R., Madella M., Vidal-Torrado P., Otero X.L., Macias F., Osterrieth M. 2013a. Opal 
Phytolith Extraction in Oxisols. Quaternary International, 287:56-62.

Calegari M.R., Madella, M., Vidal-Torrado P., Pessenda, L.C.R., Marques F.A., 2013b. Combining Phytolith and $\delta^{13} \mathrm{C}$ matter in Holocene Paleoenvironmental Studies of Tropical Soils: An Example of an Oxisol in Brazil. Quaternary International, 287:47-55.

Calegari M.R., Raitz E., Paisani J.C. 2011. Coleção de referência de fitólitos da Floresta Ombrófila Mista no SW do Paraná: primeira aproximação. In: Cong. Abequa, 13, 2011. Res. Expand..., Búzios, Ass. Bras. Est. do Quaternário.

Campos A. C. de, Labouriau L. F. G. 1969. Corpos Silicosos de Gramíneas dos Cerrados. II. Pesquisa Agropecuária Brasileira, 4:143-151.

Cavalcante P.B. 1968. Contribuição ao Estudo dos Corpos Silicosos das Gramíneas Amazônicas I. Panicoideae (Melinideae, Andropogoneae e Tripsaceae). Botânica, 80:1-11.

Chueng K. F. 2012. Inferência da cobertura vegetal e das condições climáticas no espinhaço meridional, MG, durante o Quaternário através dos indicadores fitólitos e isótopos de carbono. Rio de Janeiro: Univ. Est. Rio de Janeiro. 115 p. (Depart. Geografia, Monografia Geografia).

Coe H. H.G. 2009. Fitólitos como indicadores de mudanças na vegetação xeromórfica da região de Búzios/Cabo frio, RJ, durante o Quaternário. Rio de Janeiro: Univ. Fed. Fluminense. 340p. (Progr. Pós-Grad. Geologia e Geofísica Marinha, Tese Dout.).

Coe H.H.G. 2010. Use of a new phytolith index for identifying changes in palm tree cover density in the region of Búzios, Rio de Janeiro, Brazil. In: Intern. Meet. Phytolith Res., 8, Colorado, 2010. Abstracts, PaleoResearch Institute (PRI), Colorado, USA.

Coe H.H.G., Lepsch I.F. 2009. Silicofitólitos como indicadores de descontinuidades litológicas em três pedons da região de Búzios/Cabo Frio, RJ. In: Congr. Bras. Ciênc. Solo, 32, 2009. Resumos expand..., Fortaleza, Univ. Fed. Ceará.

Coe H.H.G., Osterrieth M., Borrelli, N. L., Silva A. S., Gomes J. G. 2010. Contributions of Phytolith Studies on the Identification of Soil Genesis and Environmental Changes in the Sao Joao River Basin, Rio de Janeiro, Brazil. In: Intern. Meet. Phytolith Res., 8, Colorado, 2010. Abstracts, PaleoResearch Institute (PRI), Colorado, USA.

Coe H.H.G., Chueng K.F., Osterrieth M., Santos A.S., Gomes J.G., Fonseca C.M. 2011. Gênese de solos e mudanças ambientais na bacia do rio São João, RJ, identificadas através do proxy fitólitos. In: Cong. Abequa, 13, 2011. Res. Expand..., Búzios, RJ, Ass. Bras. Est. do Quaternário.

Coe H.H.G., Chueng K.F., Gomes J.G. 2012a. Mudanças Possivelmente Antrópicas na Cobertu- ra Vegetal na Região de Búzios, Rio de Janeiro, Identificadas Através de Análises de Fitólitos. Rev. Tamoios, 7(2):60-76.

Coe H.H.G., Chueng K.F., Gomes J.G. 2012b. Reconstituições da Vegetação e Inferências de Paleoclimas Através da Utilização dos Indicadores Fitólitos e Isótopos de Carbono. Exemplos de Estudos no Brasil. Rev. Geonorte, Ed. Especial, 1(4):248-261.

Coe H.H.G., Alexandre A., Carvalho C.N., Santos G.M., Silva A.S., Sousa L.O.F., Lepsch I.F. 2013a. Changes in Holocene Tree Cover Density in Cabo Frio (Rio de Janeiro, Brazil): Evidence From Soil Phytolith Assemblages. Quaternary International, 287: 63-72.

Coe H.H.G., Sousa L.O.F., Silva A.L.C., Santos C.P., Ramos Y.B.M., Pires G.S.S., Seixas, A.P., Silvestre, C.P., Ramires J.V. 2013b. Caracterização das comunidades vegetais da restinga da APA de Maricá, RJ, através de estudos de fitólitos: resultados preliminares. In: Sem. Estudos Cost.,2, 2013. Res. Expand..., Salvador, Univ. Fed. Bahia.

Coe H.H.G., Gomes J.G., Pinto T.R.M., Pires G.S.S., Chueng K.F., Ramires, J.V., Ramos, Y.B.M. 2013c. Inferências de mudanças ambientais através de análises fitolíticas e isotópicas na bacia do rio São João, RJ, Brasil. In: Enc. Geográfos América Lat., 19, 2013, Resumés, Union Geogr. Inter. Lima, Peru.

Costa F.G.C.M. da, Bove C.P., Arruda R.C.O., Philbrick T. 2011. Silica Bodies and their Systematic Implications at the Subfamily Level in Podostemaceae. Rodriguésia. 62(4): 937-942.

Costa L.M., Santos R.F., Schaefer C.E.G.R., Moreau A.M.S., Moreau M.S. 2010a. Ocorrência de Corpos Silicosos em Horizontes Superficiais de Solos de Diferentes Ecossistemas. Rev. Bras. Ciência do Solo, 34:871-879.

Costa L.M., Moreau A.M., Moreau M.S. 2010b. Estabilidade da Sílica Biogênica Extraída de Capim Jaraguá (Hyparrhenia rufa) em Solução de $\mathrm{NaOH}$. Química Nova, 33(8):1658-1663.

Figueiredo R.C.L, Handro W. 1971. Corpos silicosos de gramíneas dos Cerrados V. In: Simp. sobre Cerrado, 3, 1971. Anais. Univ. São Paulo, São Paulo, SP.

Fonseca C.M., Gomes J.G., Coe H.H.G. 2011. Identificação de mudanças ambientais na Bacia do Rio São João, RJ, a partir da análise de fitólitos extraídos de perfis de solo. In: Simp. Brasileiro Geog. Física Apl., 14, 2011. Res. Expand..., Univ. Est. Mato Grosso do Sul, Dourados, MS.

Gomes J. G. 2012. Contribuição para a compreensão da gênese e evolução de solos na bacia do rio São João, RJ, através de análises fitolíticas. Rio de Janeiro: Univ. Est. Rio de Janeiro. 137 f. (Depart. Geografia, Monografia). 
Lepsch I.F., Andrade Paula L.M. 2006. Fitólitos em Solos sob Cerradões do Triângulo Mineiro: Relações com Atributos e Silício Adsorvido. Caminhos de Geografia, 6:185-190.

Lepsch I.F., Pinilla-Navarro A., Oliveira L. A. 2003. Soil phytholiths as related to some Brazilian dicotyledoneous cerrado species with asperous leaves. In: Congr. Bras. Ciência Solo, 29, 2003. Res. Expand..., Ribeirão Preto, Univ. Est. Paulista "Júlio de Mesquita Filho".

Lepsch I.F., Tomba A.C. 2004. Silico-fitólitos de bambus (Poaceae) e solos da parcela permanente do Parque Estadual Carlos Botelho. SP. In: Simp. Proj. Parcelas Permanentes, 3, 2004. Res. Expand..., Assis, SP, Univ. Est. Paulista "Júlio de Mesquita Filho".

Lima L. G., Medeanic S. 2007. A variação morfológica dos fitólitos de opala em duas espécies de gramíneas na Planície Costeira do Rio Grande do Sul e sua importância nas paleoreconstruções. In: Congr. Abequa, 11, 2007. Res. Expand..., Belém, Ass. Bras. Est. do Quaternário.

Madella M., Alexandre A., Ball T. 2005. International Code for Phytolith Nomenclature 1.0. Annals of Botany, 96(2) 253-260.

Medeanic S., Cordazzo C.V. Study of Phytoliths in Extant Plants in Brazil: Implications for Paleoecological Reconstructions. 2009. URL: < http:// archive.nbuv.gov.ua/portal/chem_biol/nvlnau/ Biol/2009_1/Medyanik01_09.pdf $>$ acesso: 20.02.2013.

Medeanic S., Cordazzo C.V., Correia I.C.S., Mirlean N. 2009. Notas sobre Fitólitos em Androtrichum trigynum (Spr.) Pfeiffer no Extremo Sul do Brasil: Tipos Morfológicos e uso nas Paleoreconstruções Costeiras. Gravel, 7(1):31-36.

Medeanic S., Cordazzo C.V., Correia I.C.S., Mirlean N. 2008. Os fitólitos em Gramíneas de Dunas do Extremo Sul do Brasil: Variabilidade Morfológica e Importância nas Reconstruções Paleoambientais Costeiras. Gravel, 6(2):1-14.

Medeanic S., Corrêa I. C. S., Weschenfelder J. 2007. Palinomorfos nos Sedimentos de Fundo da Laguna dos Patos, RS: Aplicação nas Reconstruções Paleoambientais. Gravel, 5(1):89-102.

Monteiro M. R., Parolin, M, Guerreiro R.L. 2011. Primeiras considerações paleoambientais com análise de fitólitos em sedimentos turfosos nos Campos Gerais do Estado do Paraná. In: Cong. Abequa, 13, 2011. Res. Expand..., Ass. Bras. Estudos Quaternário, Búzios, RJ.

Monteiro M. R., Pereira J. S. R., Rasbold G.G., Parolin M., Caxambú M. G. 2012. Morfologia de Fitólitos Característicos de duas Espécies de Arecaceae do Bioma Mata Atlântica: Bactris setosa Mart. e Geonoma schottiana Mart. Rev. Biol. Neotr., 9(1):10-18.
Monteiro M.R. 2012. Paleoambientes indicados através da análise de fitólitos e $\delta^{13} \mathrm{C}$ em sedimentos turfosos nos Campos Gerais do Estado do Paraná. Campo Mourão: Univ. Tecn. Fed. Paraná. 61p. (Depart. Engenharia Ambiental, Monografia).

Paisani J. C., Calegari M. R., Pessenda L.C.R., Paisani S.D.L., Raitz E. 2012. Dinâmica ambiental e da vegetação do Planalto das Araucárias - Superfície II - no Quaternário Tardio: contribuições das análises de fitólitos, de isótopos de carbono e da mineralogia de argila. In: Simp. Nac. Geomorfologia, 9, 2012. Res. Expand..., Univ. Fed. Rio de Janeiro, Rio de Janeiro, RJ.

Parolin M., Rasbold G.G., Pessenda L.C.R. 2011. Primeiras considerações palinológicas e paleoclimáticas do Pleistoceno Tardio na região de Campo Mourão, Paraná, Brasil. In: Cong. Abequa, 13, 2011. Res. Expand..., Búzios, RJ, Ass. Bras. Est. do Quaternário.

Paula L.M.A., Silva P.C. 2006. A formação do mineral opala biogênica nos solos dos cerradões de Uberlândia. In: Simp. Nac. Geomorfologia, 7, 2006. Res. Expand..., Belo Horizonte, Univ. Fed. Minas Gerais.

Pereira G.L. 2010. Identificação de fitólitos a partir de fragmentos de carvão. Cadernos do LEPAARQ. 7:13-14.

Pereira J.S.R., Parolin M., Monteiro M.R., Caxambu M.G., Rasbold G.G. 2013. Caracterização Morfológicas dos Fitólitos de Butia microspadix Burret (Arecaceae). Rev. Ciências Amb., 7(1): 59-66.

Piperno D. R. 2006. Phytoliths: a comprehensive guide for archaeologists and paleoecologists. Oxford: AltaMira Press, 238 p.

Piperno D. R., Becker P. 1996. Vegetational History of a Site in the Central Amazon Basin Derived from Phytolith and Charcoal Records from Natural Soils. Quaternary Research, 45(2):202-209.

Piperno D.R. 1991. The Status of Phytolith Analysis in the American Tropics. Journ. World Prehist., 5(2):155-191.

Raitz E. 2012. Coleção de referência de Silicofitólitos da flora do Sudoeste do Paraná: Subsídios para estudos paleoambientais. Francisco Beltrão: Univ. Est. Oeste do Paraná. 204p. (Progr. Pós-Grad. Geografia, Dissert. Mestrado).

Raitz E., Calegari M.R., Paisani J.C. 2012. Fitólitos da Floresta Ombrófila Mista e do Campo da região SW do Estado do Paraná: Produção e Classificação. In: Simp. Paranaense Pós-Grad. Pesq. Geografia, 6, 2012. Res. Expand..., Guarapuava, PR, Univ. Centro-Oeste do Paraná.

Rapp G.J., Mulholand S.C. (Ed.). 1992. Phytolith Systematics. New York: Plenum Press. 350 p.

Rasbold G.G., Monteiro M.R, Parolin M., Caxambú M.G., Pessenda L.C.R. 2011. Caracterização dos Tipos Morfológicos de Fitólitos Presentes 
em Butia paraguayensis (Barb. Rodr.) L. H. Bailey (Arecaceae). Iheringia, 66(2):265-270.

Rasbold G.G., Parolin M., Caxambú M.G., Pessenda L.C.R. 2012. Avaliação e Quantificação dos Fitólitos Presentes em Chloris elata Desv., Chloris gayana Kunth e Tripogon spicatus (Ness) Ekman (Chloridoideae). Iheringia, 67(2):137-148.

Rasbold G.G., Parolin M., Caxambú M. G. 2010. Avaliação das formas de fitólitos presentes em Cyperus giganteus Vahl (Cyperaceae). In: Enc. Prod. Científica Tecnológica, 5, 2010, Anais..., Fac. Est. Ciências Letras Campo Mourão, Campo Mourão, PR.

Sendulsky T.S., Labouriau L.G. 1966. Corpos silicosos de gramíneas dos Cerrados. I. In: Simp. sobre Cerrado, 1, 1966. Anais..., Academia Brasileira de Ciências, Rio de Janeiro, RJ.
Silva S.T., Labouriau L.G. 1970. Corpos Silicosos de Gramíneas dos Cerrados III. Pesq. Agrop. Brasileira, 5:167-182.

Söndahl M.R., Labouriau L.G., 1970. Corpos Silicosos de Gramíneas dos Cerrados IV. Pesq. Agrop. Brasileira, 5:183-207.

Webb E.A., Longstaffe F.J. 2000. The oxygen isotopic compositions of silica phytoliths and plant water in grasses: implications for the study of paleoclimate. Geochimica et Cosmochimica Acta, 64(5):767-780.

Wesolowski V., Souza S.M.F.M., Reinhard K. 2007. Grânulos de amido e fitólitos em cálculos dentários humanos: contribuição ao estudo do modo de vida e subsistência de grupos sambaquianos do litoral sul do Brasil. Rev. Mus. Arq. Etn., 17:191-210.

RESUMO - São aqui apresentados os resultados de um estudo analítico sobre as pesquisas com fitólitos, corpos micrométricos de opala biogênica precipitados nos tecidos vegetais, produzidas no Brasil até junho de 2013. As pesquisas sobre fitólitos são recentes no Brasil e tem aumentado consideravelmente nos últimos anos. Desta forma, o presente trabalho tem por objetivo introduzir os futuros pesquisadores sobre 0 estágio atual das pesquisas com esse tema. Como metodologia de pesquisa foi utilizado o buscador de periódicos da CAPES, bem como informações para monografias e artigos adquiridas com pesquisadores em âmbito nacional e internacional. Os resumos simples publicados em eventos não fizeram parte do levantamento. Os resultados indicaram que as pesquisas de aplicação (como dado proxy) têm sido mais numerosos $(63,5 \%)$ que aqueles relativos a identificação de fitólitos em plantas modernas (36,5\%), evidenciando a urgência de pesquisas com essa finalidade. Embora os fitólitos sejam muito utilizados nos estudos arqueológicos, no Brasil foram publicados apenas dois trabalhos. Por fim, realizou-se a espacialização das pesquisas, a qual demonstrou a grande disparidade na produção científica, que, não obstante, se concentram em maior parte na Região Centro-Sul do Brasil, mais precisamente nos estados do Rio de Janeiro, Paraná, Minas Gerais e Rio Grande do Sul.

PALAVRAS-CHAVE: Silicofitólitos, Plantas modernas, Reconstrução paleoambiental. 